\title{
Sistem Computer Vision Pengenalan Pola Angka dan Operator Matematika Pada Permainan Kartu Angka Berbasis Jaringan Syaraf Tiruan Perceptron
}

\author{
Rian Rahmanda Putra ${ }^{1)}$, Fery Antony ${ }^{2)}$ \\ 1) 2) Program Studi Sistem Komputer Universitas Indo Global Mandiri \\ Jalan Jendral Sudirman No. 629 KM 4 Palembang Kode Pos 30129 \\ Email: rian@uigm.ac.id ${ }^{1)}$, feryantony@uigm.ac.id ${ }^{2)}$
}

\begin{abstract}
Computer vision is an image processing by a computer to obtain information from image captured through the camera generally used in real-time application. This paper reports on the results of research conducted on computer vision system designed to be able to recognize the image number (0-9) and mathematical operators (addition (+) and subtraction (-)) in a card number figures. Computer vision system designed in this study consists of a camera on the android phone that used to captured images on the card number and the computer that has artificial neural network perceptron algorithm in identifiying images. Both components of the computer vision system are connected wirelessly through the TCP/IP Protocol. At the training stage of Perceptron ANN, 10 samples for each number and mathematical operators are used. Computer vision system built in this study also have several image processing techniques such as greyscalling, thresholding, cropping and resizing. This techniques is used to filter the information from the images captured by camera in order to get the adequate and smaller image to be processed by ANN Perceptron. Stages of testing performed three times. First testing is given picture numbers 0-3, second testing is given picture number 4-7 and third testing is given number 8-9, addition symbol and subtraction symbol. Based on testing result, system built are able to recognize 10 from 12 image rendered with a success rate of $83.33 \%$.
\end{abstract}

Keywords : Computer vision, perceptron, card number

\begin{abstract}
Abstrak
Computer vision merupakan proses pengolahan citra oleh computer untuk mendapatkan informasi dari citra yang ditangkap melalui kamera yang umumnya digunakan pada aplikasi waktu nyata. Tulisan ini melaporkan tentang hasil penelitian yang dilakukan tentang sistem computer vision yang dirancang untuk dapat mengenali gambar angka (0-9) dan operator matematika(penjumlahan $(+)$ dan pengurangan (-)) pada permainan kartu angka. Sistem computer vision yang dirancang pada penelitian ini terdiri dari kamera pada ponsel android yang digunakan untuk menangkap gambar pada kartu angka dan komputer yang memiliki algoritama Jaringan Syaraf Tiruan Perceptron dalam melakukan identifikasi gambar. Kedua komponen sistem computer vision tersebut dihubungkan memlaui jaringan wireless melalui protocol TCP/IP. Pada tahapan pelatihan JST perceptron, digunakan 10 sample citra untuk masing - masing angka dan operator matematika yang akan dikenali oleh sistem. Pada penelitian ini juga dilakukan tahapan pemrosesan citra sebelum diolah oleh JST Perceptron baik dalam tahapan pelatihan maupun pada saat sistem dijalankan. Tahapan pengolahan citra yang digunakan pada penelitian ini adalah greyscalling, thresholding, cropping dan resizing. Hal ini dilakukan untuk menyaring informasi pada citra yang ditangkap oleh kamera agar didapatkan citra yang berukuran kecil dengan informasi yang lengkap untuk diproses oleh JST Perceptron. Pada saat sistem diuji coba, diberikan 4 deret kartu angka di depan kamera. Pada pengujian pertama diberikan gambar angka 0-3, pengujian kedua diberikan gambar angka 4-7 dan pada pengujian ketiga diberikan angka 8-9 serta gambar operator penjumlahan dan pengurangan. Berdasarkan pengujian yang dilakukan, sistem computer vision yang dirancang mampu mengenali 10dari 12 gambar yang diberikan dengan tingkat keberhasilan sebesar $83.33 \%$.
\end{abstract}

Kata Kunci : computer vision, perceptron, kartu angka 


\section{Pendahuluan}

Konsep computer vision meniru cara kerja sistem visual manusia tentang bagaimana manusia dapat melihat objek melalui indra penglihatan (mata) hingga objek yang ditangkap oleh mata diteruskan ke otak untuk diintepretasikan sehingga manusia dapat mengetahui objek yang tampak dari pandangan mata (Wijaya \& Prayudi, 2010).

Computer vision dapat dibangun menggunakan kamera sebagai mata dan komputer sebagai unit pemrosesannya. Pengolahan informasi pada otak manusia berdasarkan pada pengetahuan yang didapat melalui proses pembelajaran. Proses pembelajaran tersebut melibatkan ribuan jaringan syaraf yang terdapat pada otak. Proses pembelajaran tersebut melibatkan ribuan jaringan syaraf pada manusia. komputer mampu meniru tingkah laku proses pembelajaran pada manusia menggunakan jaringan syaraf tiruan (JST).

JST memiliki banyak model algoritma, salah satunya adalah perceptron. Perceptron adalah salah satu algoritma JST yang digunakan untuk melakukan klasifikasi secara linear (Gallant, 1990). Algoritma JST perceptron banyak digunakan dalam aplikasi pengenalan citra dari suatu objek (Pujiyanta, 2009; Sunyoto \& Harjoko, 2014; Wibowo \& Wirakusuma, 2013). Computer vision juga dikembangkan sebagai media pengajaran seperti, simulasi terjadinya tsunami (Priyatna, Putri, Parlindungan, \& Renita, 2014), alat peraga organ dalam manusia (Bachtiar \& Haryanto, 2015) pengenalan hewan untuk pendidikan taman kanak - kanak (Untiasarani, 2015) dan prediksi pencapaian karir mahasiswa (heryati dkk, 2018).

Tulisan ini melaporkan hasil penelitian yang telah dilakukan tentang sistem computer vision yang dapat mengenali angka dan operator matematika yang terdapat pada permainan kartu angka berbasis JST Perceptron. Sistem computer vision yang dibangun terdiri dari kamera pada ponsel android yang dihubungkan dengan komputer yang memiliki algoritma pengenalan pola dengan JST perceptron melalui protocol TCP/IP secara wireless.

\section{A. Computer Vision}

Computer vision adalah integrasi dari proses akuisisi citra, pengolahan citra, pengenalan dan pembuatan keputusan yang digunakan untuk persepsi visual (Wijaya \& Prayudi, 2010). Computer vision mencoba meniru cara kerja sistem visual manusia, bagaimana manusia dapat melihat objek dengan mata, kemudian citra objek diteruskan ke otak untuk diintepretasi sehingga manusia dapat mengetahui objek apa yang tampak dalam pandangan mata dan selanjutnya hasil intepretasi digunakan untuk pengambilan keputusan (Szeliski, 2010).

Tahapan awal yang dilakukan oleh komputer dalam mengenali objek adalah tahapan segmentasi. Segmentasi adalah tahapan pemisahan citra menjadi bagian - bagian yang diharapkan merupakan objek - objek tersendiri dengan cara membagi suatu wilayah pada citra berdasarkan kriteria kemiripan tertentu antara derajat keabuan piksel - piksel terdekat (Darmawan, 2009). selanjutnya hasil intepretasi digunakan untuk pengambilan keputusan (Szeliski, 2010). Tahapan awal yang dilakukan oleh komputer dalam mengenali objek adalah tahapan segmentasi. Segmentasi adalah tahapan pemisahan citra menjadi bagian - bagian yang diharapkan merupakan objek - objek tersendiri dengan cara membagi suatu wilayah pada citra berdasarkan kriteria kemiripan tertentu antara derajat keabuan piksel - piksel terdekat (Darmawan, 2009).

\section{B. JST Perceptron}

Model JST Perceptron ditemukan oleh (Rosenblatt, 1962) dan (Minsky \& Papert, 1969). Perceptron banyak digunakan dalam berbagai aplikasi pengenalan pola (Pujiyanta, 2009; Sunyoto \& Harjoko, 2014; Susmikanti, 2010; Wibowo \& Wirakusuma, 2013). Perceptron memiliki kemiripan dengan arsitektur jaringan Hebb. Percpetron terdiri dari bebrapa unit masukan dan memiliki sebuah unit keluaran. Fungsi aktivasi percpetron bukan merupakan fungsi biner tetapi memiliki kemunngkinan nilai $-1,0$ atau 1 .

Perceptron memiliki tujuan agar klasifikasi setiap pola masukan ke dalam kelas tertentu. Apabila outputnya +1 , maka masukan yang diberikan termasuk dalam kelas tertentu, sebaliknya jika outputnya -1 , maka masukan yang diberikan tidaak termasuk dalam kelas tertentu. Arsitektur perceptron digambarkan seperti yang tampak pada gambar 1 .

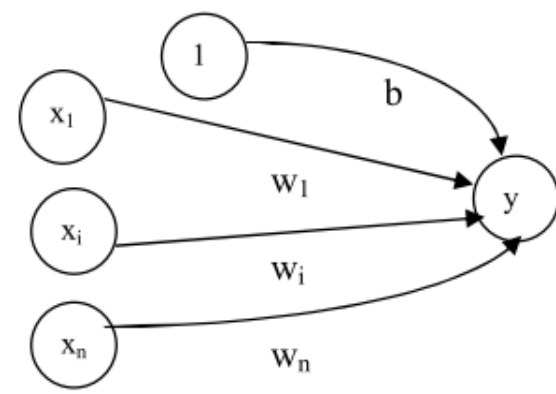

Gambar 1. Arsitektur Perceptron Sederhana (Pujiyanta, 2009)

Bobot koneksi dari unit assosiator ke unit response ditentukan melalui pelatihan perceptron. Setiap masukan training jaringan akan menghitung response dari unit output, kemudian jaringan akan menghitung response dari unit output, kemudian jaringan akan menentukan apakah suatu error terjadi pada pola tersebut dengan cara membandingkan output hasil perhitungan dengan nilai targetnya. Jaringan tersebut akan membedakan error antara output hasil perhitungan 0 dengan target -1 atau outputnya +1 dengan target -1 . Tanda dari error menunjukkan bahwa bobot koneksi harus diubah dalam arah yang dinyatakan oleh nilai target. Namun demikian, hanya bobot pada koneksi dari unti pengiriman sinyal selain 0 ke unit output yang akan disesuaikan nilainya, karena hanya sinyal tersebut yang menambah error. Jika 
error tidak terjadi maka bobot-bobot tersebuut tidak akan diubah tetapi sebaliknya jika suatu error terjadi untuk pola masukan pelatihan tertentu, bobot - bobot akan diubah menurut persamaan 1 dan 2 .

$$
w_{i}(n e w)=w_{i}(o l d)+\alpha t x_{i}
$$

Keterangan:

$$
\begin{array}{ll}
\mathrm{x}_{\mathrm{i}} & =\text { masukan ke } \mathrm{i} \\
\mathrm{t} & =\text { target yang nilainya }+1 \text { atau }-1 \\
\alpha & =\text { kecepatan belajar (learning rate), yaitu yaitu } \\
& 0<\alpha \leq 1 \\
\mathrm{w} & =\text { bobot }
\end{array}
$$

$$
b(\text { new })=b(\text { old })+a t
$$

Keterangan:

$$
\begin{aligned}
\mathrm{b} & =\text { bias } \\
\alpha & =\text { keccepatan belajar (learning rate) yaitu } 0< \\
& \alpha \leq 1 \\
\mathrm{t} \quad & =\text { target yang nilainya }+1 \text { atau }-1
\end{aligned}
$$

Jika error tidak terjadi, maka bobot tidak akan berubah. Algoritma perceptron yang digunakan memiliki susunan sebagai berikut:

1. Inisalisasi nilai bobot, bias dan nilai learning state

2. Selama ada elemen vektor masukkan yang respon unit keluarannya tidak sama dengan target, maka akan dilakukan set aktivasi unit masukkan dan menghitung respon unit keluarannya

3. Perbaiki nilai bobot pola yang memiliki kesalahan dimana nilai $\mathrm{y} \neq \mathrm{t}$, menggunakan persamaan 1 dan 2 .

\section{Kartu Angka}

Kartu angka adalah media visual dua dimensi pada bidang yang tidak transparan, yang dapat digunakan untuk mempermudah anak dalam memahami informasi yang terkandung dalam gambar yang disertai angka(Wulandari, Wirya, \& Tirtayani, 2014). Kartu angka dapat merangsang anak dapat lebih cepat mengenal angka, membuat minat anak semakin menguat dalam menguasai konsep bilangan, serta merangsang kecerdasan dan ingatan anak, sehingga kartu angka merupakan media yang memberikan dampak positif terhadap upaya peningkatan kemampuan operasi bilangan pada anak (Septiyana, 2012). Penerapan media belajar melalui kartu angka dapat meningkatkan kemampuan kognitif anak (Apsari, 2012)(Parwati, Parmiti, \& Jampel, 2013).

\section{Pembahasan}

\section{A. Arsitektur Sistem Computer Vision}

Arsitektur sistem computer yang dibangun dapat dilihat pada gambar 2. Kamera yang digunakan adalah kamera yang terdapat pada ponsel android. Konfigurasi kamera menggunakan software IP webcam yang dipasang pada ponsel android. Software IP webcam memungkinkan kamera pada ponsel android bekerja layaknya kamera cctv berbasis IP (Internet Protocol). Kamera akan mengirim aliran gambar yang ditangkap ke komputer menggunakan protocol TCP/IP secara wireless melalui alamat url. Pada penelitian digunakan alamat url http://192.168.43.1:8080/ video.

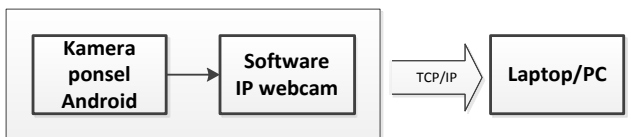

Gambar 2. Arsitektur Sistem Computer Vision

\section{B. Pengembangan Software}

Perangkat lunak pada penelitian ini bertujuan untuk melakukan proses pengolahan citra dan pengenalan pola (JST Perceptron). Kedua tahapan tersebut dijelaskan pada sub bab berikut ini. Software akan dibangun dengan menggunakan bahasa pemrograman C\#.

\section{Pengolahan Citra}

Pengolahan citra pada penelitian ini terdiri dari proses grayscaling, thresholding, cropping image dan resizing image. Tahapan grayscaling digunakan untuk menghasilkan citra keabuan dari citra RGB. Pada dasarnya , citra RGB memiliki 4 komponen yang terdiri dari Alpha (A), Red(R), Green(G) dan Blue (B). Komponen Alpha merupakan nilai transparansi citra sedangkan komponen R, G dan B merupakan nilai warna yang terdapat dalam sebuah piksel. Proses grayscalling dilakukan dengan merata-ratakan nilai dari komponen R,G dan B.

Setelah mendapatkan nilai keabuan dari sebuah citra, tahapan selanjutnya adalah melakukan proses thresholding untuk menghasilkan citra biner. Citra biner adalah citra yang hanya memiliki nilai 0 dan 1 pada setiap pikselnya yang merepresentasikan warna hitam dan putih. Citra biner didapatkan dengan memberikan nilai thresholding pada tiap piksel pada citra keabuan. Apabila nilai piksel tersebut berada dibawah nilai thresholding $(\mathrm{f}(\mathrm{x}, \mathrm{y})<\mathrm{T})$ maka nilai piksel tersebut akan ditetapkan sebagai hitam atau 1 dan sebaliknya, jika nilai piksel tersebut berada di atas nilai threshold $(\mathrm{f}(\mathrm{x}, \mathrm{y})>\mathrm{T})$ maka nilainya akan ditetapkan sebagai 0 atau putih.

Setelah mendapatkan citra biner, proses yang selanjutnya dilakukan adalah melakukan cropping dan resizing pada citra tersebut agar memudahkan pada tahapan JST perceptronnya. Cropping adalah proses memotong citra pada bagian yang memiliki informasi yang akan digunakan dan proses resizing adalah proses memperkecil ukuran citra. Ukuran awal citra tersebut adalah $640 \times 480$ piksel. Setelah proses resixing ukurannya akan direduksi menjadi 20x20 piksel. Cropping image dilakukan dengan cara mencari setiap sisi (atas, bawah, kanan, kiri) dari citra angka atau operan matematika.

\section{Pengenalan Pola}

Sistem computer vision yang dibangun pada penelitian ini menggunakan algoritma Jaringan Syaraf Tiruan (JST) Perceptron dalam melakukan proses pengenalan pola pada citra angka dan operator matematika yang tertera pada permainan kartu angka. JST Perceptron terlebih dahulu dilatih dengan menggunakan data sample citra angka dan operator 
matematika yang telah disiapkan. Proses pelatihan akan menghasilkan nilai bias dan bobot. Nilai bias dan bobot inillah yang digunakan oleh JST dalam menentukan pola gambar ketika sistem dijalankan. Dalam Algoritma JST percpetron, ada 3 langkah penting untuk mendapatkan nilai bobot akhir. Langkah pertama adalah mendapatkan nilai y_in. Nilai y_in adalah nilai net input yang nantinya akan diproses lebih lanjut oleh sistem aktivasi F. Nilai y_in didapatkan dengan menggunakan persamaan 1 .

$$
\text { y_in }=b+\sum x \text { i.wi }
$$

Setelah mendapatkan nilai y_in, maka y_in akan dimasukkan ke dalam fungsi aktivasi. Fungsi aktivasi f merupakan fungsi yang akan mengasilkan output. Fungsi aktivasi ditunjukkan pada persamaan 2. Pada penelitian ini menggunakan nilai $\theta$ sebesar 0.3 .

$$
f\left(y_{-} \text {in }\right)=\left\{\begin{array}{l}
1 \text { jika y_in }>\theta \\
-1 \text { jika y_in }<-\theta
\end{array}\right.
$$

Setelah mendapatkan nilai $\mathrm{f}(\mathrm{y}$ _in) dari fungsi aktivasi, langkah selanjutnya adalah mebandingkan nilai $\mathrm{f}(\mathrm{y}$ _in) dengan target yang ditentukan. Jika nilai $\mathrm{f}(\mathrm{y}$ _in) sama dengan nilai target, maka bobot dan bias tetap, namun jika nilai $\mathrm{f}(\mathrm{y}$ _in) tidak sama dengan nilai target, maka akan ada perubahan nilai bobot dan bias. Perubahan nilai bias dan bobot mengikuti aturan pada persamaan 1 dan 2 .

Perhitungan nilai bobot dan bias akan terus berlangsung selama nilai $\mathrm{f}(\mathrm{y}$ _in) tidak sama dengan target. Ketika nilai $\mathrm{f}(\mathrm{y}$ _in) sama dengan target, maka proses perhitungan dengan rumus diatas akan dihentikan dan nilai bobot dan bias terakhirlah yang disimpan dan digunakan pada saat sistem bekerja. Pada penelitian ini, nilai awal bobot dan bias ditentukan bernilai 0 , nilai threshold diberikan nilai 128 dan learning rate diberikan nilai sebesar 0.1. Tidak ada aturan yang baku pada penentuan nilai tersebut. Jika saat pengujian hasil pelatihan nya kurang baik nilai ini akan kembali diubah. Tampilan interface perangkat lunak dapat dilihat pada gambar 3.

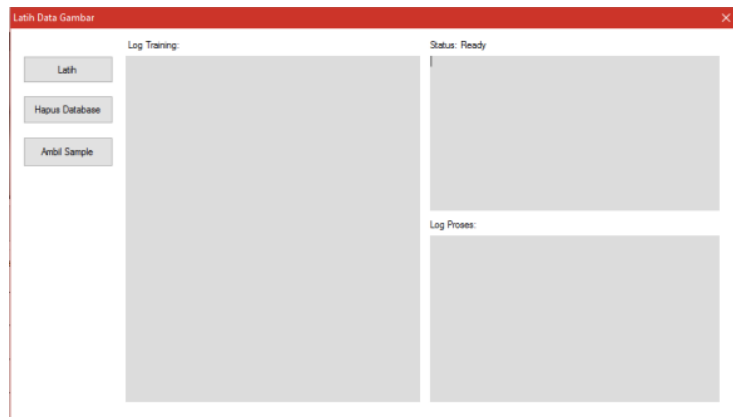

Gambar 3. Tampilan interface pada tahapan pelatihan

Setelah proses pelatihan dilakukan selesai, maka sistem computer vision akan dijalankan untuk mengukur sebaik apa JST perceptron dalam mengenali pola citra yang telah diberikan. Interface pada saat sistem dijalankan dapat dilihat pada gambar 4.

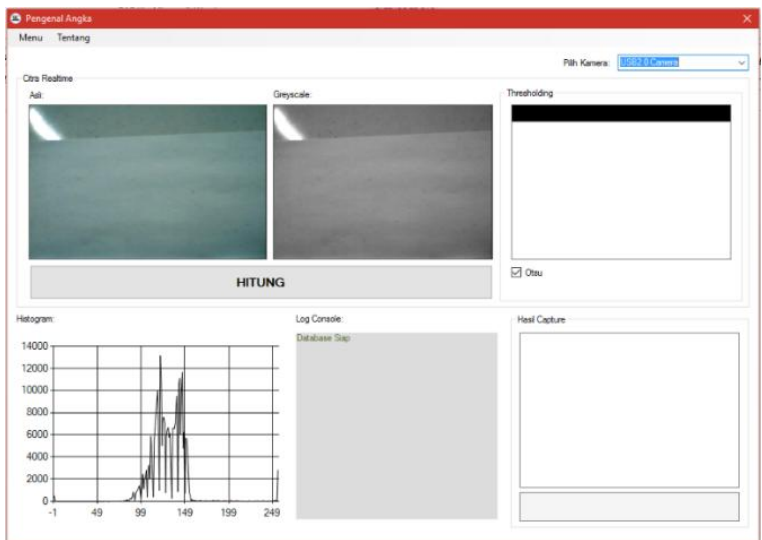

Gambar 4. Interface Pada saat sistem dijalankan

\section{E. Pengujian}

Pengujian dilakukan untuk melihat akurasi sistem dalam mengenali pola angka dan operator matematika yang telah diberikan pada saat proses pelatihan. Tingkat keberhasilan JST Perceptron dalam mengenali pola yang diberikan dihitung dengan menggunakan persamaan 5 .

$$
\%=\frac{\text { Iumlah benar }}{\text { Iumlah Citra pengujian }} \times 100 \%(5)
$$

\section{F. Pengujian Pertama}

Pegujian pertama dilakukan untuk melihat apakah jaringan perceptron dapat mengenali angka 0,1,2 dan 3 . Proses percobaan dan hasilnya dapat dilihat pada gambar 3. Pada pengujian pertama, dapat dilihat pada gambar 5 bahwa computer vision yang bangun dapat mengenali seluruh angka yang diberikan. Dengan Dengan menggunakan persamaan 5, didapatkan bahwa tingkat keberhasilannya adalah $100 \%$.

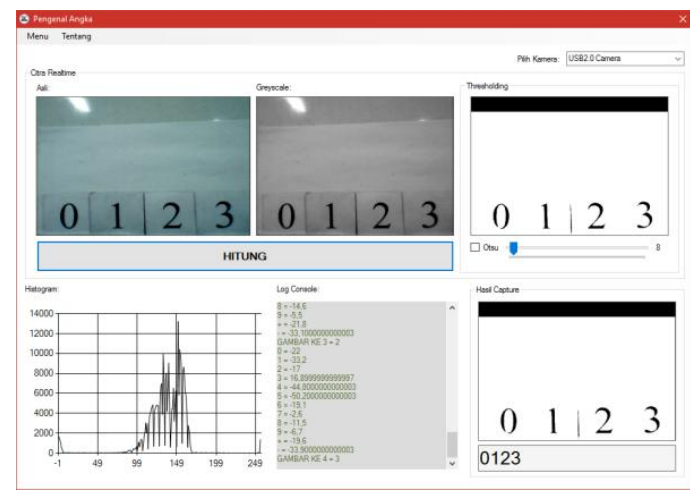

Gambar 5. Pengujian Pertama

\section{G. Pengujian Kedua}

Pada pengujian kedua, dilakukan pengujian untuk melihat apakah jaringan perceptron dapat mengenal angka 4,5,6 dan 7. Proses pengujian dan hasil dari pengujian kedua, dapat dilihat pada gambar 4. Pada pengujian kedua, dapat diihat pada gambar 6 bahwa computer vision hanya dapat mengenali angka 6 dan 7 saja, sedangkan angka 4 tidak terdekteksi dan angka 5 
dikenali sebagai angka 7. Dengan menggunakan persamaan 5, dapat dilihat bahwa pada pengujian kedua ini, tingkat keberhasilannya sebesar $50 \%$.

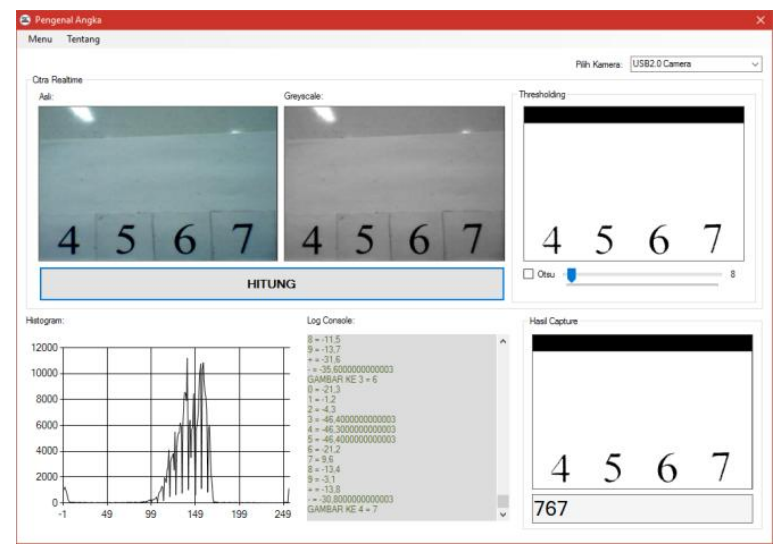

Gambar 6. Pengujian Kedua

\section{H. Pengujian Ketiga}

Pada pengujian ketiga, dilakukan pengujian untuk melihat apakah computer vision yang dibangun dapat mengenali angka 8,9 dan 0 serta operator penjumlahan (+) dan pengurangan (-). Proses pengujian dan hasil pengujian dapat diihat pada gambar 7 . Pada pengujian ketiga, dapat dilihat bahwa computer vision dapat mengenali seluruh pola gambar yang diberikan. Dengan menggunakan persamaan 5, didapat dilihat bahwa tingkat keberhasilan pada pengujian ini adalah $100 \%$.

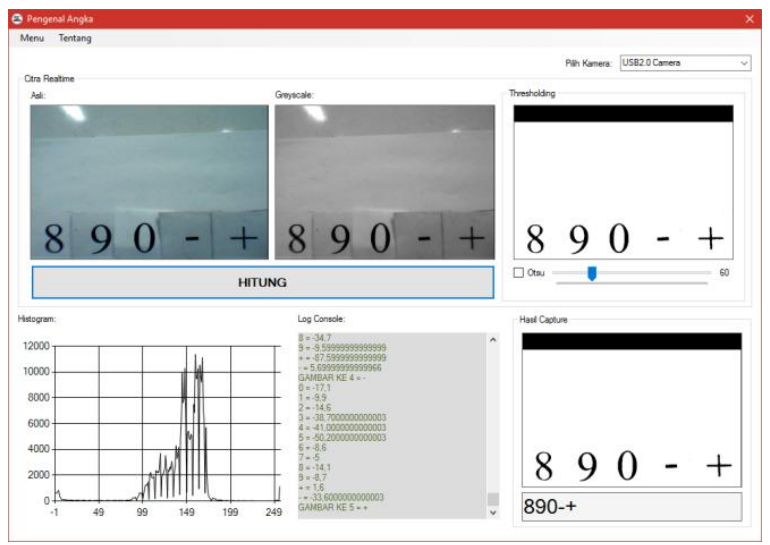

Gambar 7. Pengujian Ketiga

\section{Hasil Pengujian}

Berdasarkan pengujian yang telah dilakukan, sistem computer vision telah dapat mengenali 10 dari 12 pola citra yang terdapat pada kartu angka yang telah dilatihkan pada JST Perceptron. Sistem tidak mampu mengenali angka 4 dan 5. Ketika diberikan citra angka 4 pada sistem, sistem tidak mampu mengenali citra tersebut. Hal ini dapat dilihat pada gambar 6 dimana hasil keluaran dari JST tidak ada yang sesuai dengan target ketika diberikan citra angka 4. Sedangkan ketika sistem diberikan citra angka 5, hasil keluaran dari JST Perceptron mengenali citra angka 5 sebagai citra angka 7. Hal ini terjadi kemungkinan dikarenakan pengaruh nilai thresholding pada tahapan pengolahan citra, namun hal ini belum dapat dipastikan dikarenakan pada tahapan pengujian ini hanya digunakan nilai thresholding yang statik. Secara keseluruhan dari tiga kali pengujian dapat dilihat bahwa tingkat keberhasilan sistem computer vision dalam mengenali pola citra pada kartu angka adalah sebesar $83.33 \%$.

\section{Kesimpulan}

Berdasarkan pengujian yang dilakukan, sistem computer vision yang dibangun telah mampu mengenali pola citra yang terdapat pada kartu angka dengan baik dengan tingkat keberhasilan sebesar $83.33 \%$.

\section{Daftar Pustaka}

Apsari, T. E. R. 2012. Upaya Meningkatkan Kemampuan Kognitif Anak Melalui Permainan Kartu Angka dan Gambar Pada Anak Kelompok B di TK Kanisisu Sidowayah Klaten Tahun Ajaran 2012/2013.

Bachtiar, M. Y., \& Haryanto, H. 2015. Perancangan Aplikasi Berbasis Markerless Augmented Reality Untuk Alat Peraga Organ Dalam Manusia Pada Sekolah Menengah Atas, 1-5.

Darmawan, M. W. 2009. Identifikasi Mutu Buah Mangga Arum Manis Berdasarkan Warna Menggunakan Image Processing dan JST. Universitas Gadjah Mada.

Gallant, S. I. 1990. Perceptron-Based Learning Algorithms. IEEE Transcation On Neural Networks, 1(2), 179-191.

Heryati.Agustina, Erduandi, Terttiaavini. 2018. Penerapan Jaringan Saraf Tiruan Untuk Memprediksi Pencapaian Prestasi Mahasiswa. Konferensi Nasional Sistem Informasi (KNSI) 2018. Universitas atmaluhur : 1158-1163

Minsky, M. L., \& Papert, S. 1969. Perceptrons: An Introduction to Computational Geometry. Handbook of attachment Theory research and clinical (Vol. 165, p. 258). doi:10.1109/T-C.1969.222718

Parwati, N. N., Parmiti, D. P., \& Jampel, I. N. 2013. Penerapan Pembelajaran Picture And Picture Berbantuan Media Kartu Angka Bergambar Dapat Meningkatkan Kemampuan Kognitif. Jurnal Pendidikan Anak Usia Dini Undiksha, 1(1).

Priyatna, A. N., Putri, L. T., Parlindungan, M., \& Renita, T.2014. Implementasi Augmented Reality Sebagai Media Pembelajaran Pada Simulasi Terjadinya Tsunami.

Pujiyanta, A. 2009. Pengenalan Citra Objek Sederhana Dengan Jaringan Saraf Tiruan Metode Perceptron, 3(1), 268-277.

Rosenblatt, F. 1962. A comparison of several perceptron models. Self-Organizing Systems, 463-484.

Septiyana, R. 2012. Peningkatan Kemampuan Operasi Bilangan (1-20) Melalui Media Kartu Angka Pada Kelompok B di TK Pertiwi 53 Geblag Bantul Yogyakarta. Universitas Negeri Yogyakarta. 
Sunyoto, A., \& Harjoko, A. 2014. Pengenalan Simbol Jarimatika Menggunakan Orientasi Histogram dan Multi-layer Perceptron. Citec Journ

Susmikanti, M. 2010. Pengenalan Pola Berbasis Jaringan Syaraf Tiruan Dalam Analisa CT Scan Tumor Otak Beligna. Seminar Nasional Aplikasi Teknologi Informasi (SNATI 2010).

Szeliski, R. 2010. Computer vision: algorithms and applications. Springer Science \& Business Media.

Untiasarani, M. Q. 2015. Pembangunan Perangkat Lunak Interaktif Berbasis Markerless Augmented Reality Untuk Pengenalan Hewan Pada Taman Kanak Kanak, 1-5.

Wibowo, M. C., \& Wirakusuma, S. 2013. Pengenalan Pola Tulisan Tangan Aksara Jawa "Ha Na Ca Ra Ka" Menggunakan Multi Layer Perceptron, 27-32.

Wijaya, T. A., \& Prayudi, Y. 2010. Implementasi Visi Komputer dan Segmentasi Citra Untuk Klasifikasi Bobot Telur Ayam RAs. Seminar Nasional Aplikasi Teknologi Informasi, 1-5.

Wulandari, P. D., Wirya, I. N., \& Tirtayani, L. A. 2014. Penerapan Numbered Head Together Berbantuan Media Kartu Angka Untuk Meningkatkan Kemampuan Mengenal Lambang Bilangan Anak. EJournal PG-PAUD Universitas Pendidikan Ganesha, 2(1). 